\title{
AS ASPIRAÇÕES REGIONALISTAS E A GEOGRAFIA ${ }^{1}$
}

\author{
CAMILle VAlLauX
}

\section{Um mea-culpa}

Há aproximadamente trinta anos, homens políticos e geógrafos entraram em acordo sobre uma grande descoberta.

Eles perceberam que a divisão departamental decretada em 1790 pela Assembleia Constituinte não mais convinha à França, e que era necessário substituir essa divisão por uma outra, mais apropriada às necessidades da sociedade moderna, diziam os homens políticos, e mais adaptada aos agrupamentos indicados sobre o solo francês pela natureza e pela história, diziam os geógrafos.

As preocupações práticas dos primeiros não eram então exatamente da mesma ordem que as preocupações científicas dos segundos. Os homens políticos acusavam os departamentos, seja de favorecer a centralização ao extremo, seja de manter nas suas escolhas eleitorais o mais incômodo espírito provinciano: exorcizavam-se então os charcos estagnados que, parece, retornavam depois, celebrados. Os geógrafos criticavam os departamentos pelo recorte arbitrário e uniforme que ora fragmentava as unidades naturais e históricas, ora justapunha os pays $^{2}$ ou os agrupamentos heterogêneos. Mas, quaisquer que fossem suas motivações particulares, políticos e geógrafos concordavam em recomendar uma nova divisão do solo da França em regiões.

\footnotetext{
${ }^{1}$ Versão original: Vallaux, Camille. 1923. Les aspirations régionalistes et la Géographie. Mercure de France, ${ }^{\circ} 723$, ano 39, vol. CCV, 1 ago. 1923. Tradução: Willian Moraes Antunes de Sousa, Rogério Haesbaert e Juliana Nunes Rodrigues.

${ }^{2}$ Sobre a multiplicidade de conotações da designação "pays", muitas vezes confundida com "região" em português e que optamos por manter em francês nesta tradução, ver, para a noção mais específica de "pays": Gallois, Lucien, Régions naturelles et noms de pays. Étude sur la région parisienne, Paris: CTHS, 2008; para a noção de "agrupamentos regionais": Vidal de la Blache, Paul, Régions françaises, Revue de Paris, 15 dez. 1910 (tradução para o português em Haesbaert, R.; Pereira, S. e Ribeiro, G. [org.] Vidal, Vidais: textos de Geografia humana, regional e política. Rio de Janeiro: Bertrand Brasil, 2012); e para a noção de "regiões econômicas": Hauser, Henri, Projet de division de la France en régions économiques, Paris: Imprimerie nationale, ago. 1917. (N.T.)
} 
Eles não estavam sendo igualmente sinceros. Os políticos se lançaram em manifestações verbais. Os geógrafos, persuadidos de que "o momento tinha chegado", debruçaram-se sobre seus mapas e se puseram com uma alegria infantil a traçar demarcações e a propor planos de divisão.

Traçar linhas arbitrárias sobre o papel, que suporta tudo, é um dos divertimentos mais caros aos fazedores de mapas. O bom e o ingênuo rei Luis XVI acabou por se reconciliar com a Revolução no dia em que ele pôde desenhar e apresentar à Assembleia Constituinte um belo mapa da França dividida em departamentos.

Pierre Foncin e Paul Vidal de la Blache publicaram na Revue de Paris planos de divisão regional da França. Este último, que tinha discípulos e alunos, entre os quais eu me encontrava, os fez trabalhar. Tenho na minha consciência um esboço de organização regional da Bretanha, que era a parte da França que eu melhor conhecia (1913). Durante duas décadas, a escola geográfica francesa não fazia muita coisa além de monografias regionais.

No entanto, o acordo sobre essa questão não era unânime.

Albert Métin, ele mesmo geógrafo, mas também homem de Estado habituado a uma visão direta das coisas e dos homens, dizia com certo desdém a propósito dos planos de Vidal: "Isso é ideia de geógrafo".

Desde 1920, depois de refletir, eu mesmo fui levado a fazer fortes reservas sobre o valor e a conveniência da divisão regional (Rivières, pays et maisons de France d'après Jean Brunhes, na Géographie de fevereiro de 1921).

Com efeito, sob diversos aspectos, o regionalismo se tornava um estado de espírito que não se nutria das conveniências políticas, nem do espírito científico. Ele se transformava em uma máquina de guerra contra a unidade francesa. A catástrofe de 1914-1918 pareceu a certo número de regionalistas, separatistas acanhados ou assumidos, uma excelente ocasião para abalar uma unidade cimentada por séculos. A coisa foi tentada mais ou menos abertamente. À luz do equívoco, os trabalhadores a favor do desmantelamento se encorajaram. Para a Alsácia, separada durante quarenta e sete anos e mal incorporada à pátria francesa, os ânimos foram completamente inflamados. Os regionalistas se proclamaram autonomistas; isso significa que essas pessoas querem fazer exatamente o contrário do trabalho de unificação completado em 1790 pela Assembleia Constituinte.

Nem Briand, nem Hennessy, nem Foncin, nem Vidal de la Blache tinham desejado isso.

Convém então revisar as noções de base que lhes serviram de ponto de partida. Revisão dos valores, revisão das justificações. Há de se discernir, nas aspirações regionalistas, o que há de legítimo e o que há de pernicioso. Tentarei fazê-lo do ponto de vista da geografia, mas não apenas do ponto de vista da geografia: se encontro no meu caminho a política e a religião, não recuarei diante delas. 


\section{O que é a região? A região e o pays?}

Entendemos por região natural uma extensão de território onde as características gerais da paisagem, estrutura de solo, relevo, clima, distribuição das águas, vegetação, mostram ter relações quase constantes e fáceis de enquadrar em uma definição de conjunto.

Assim, o Oeste francês, compreendendo a Bretanha, o Cotentin e a Vendée, com suas rochas na maior parte compactas, seu relevo desgastado, seu clima ameno, equilibrado e úmido, sua vegetação de charneca, de pradarias e de campos fechados, forma uma região natural.

A Champagne calcária, plana, permeável, seca, de águas raras e concentradas, vegetação pobre de charneca para as ovelhas, forma uma região natural.

O Maciço Central, vasta protuberância de solo rico em silício, dominado por asperezas eruptivas, país de "terras frias", com suas tensas tempestades de verão, suas neves e suas rigorosas temperaturas de inverno, suas encostas de castanheiras, suas platières ${ }^{3}$ e suas restivas, forma uma região natural.

Se as definições puramente físicas são bastante fáceis, com a condição de se deixar à margem características secundárias que às vezes neutralizam as outras, as demarcações são menos simples.

Há apenas algumas regiões de montanha cujos limites com regiões vizinhas são relativamente fáceis de traçar, pois a passagem de umas às outras se faz em um espaço muito pequeno. Mesmo sobre as vertentes onde as encostas são das mais suaves, as montanhas parecem se elevar das planícies sobre uma linha hipsográfica bem determinada que o atalho das perspectivas ajuda nossos olhos a traçar (limite norte do Maciço Central, limites do maciço alpestre em direção à planície do Ródano).

Existem então grandes quadros naturais que uma visão sintética pode caracterizar completamente, ainda que fora das regiões montanhosas seja difícil traçar limites. São esses quadros que nós chamamos de regiões.

Mas, quais relações existem entre as regiões naturais e os grupos humanos dos quais elas constituem o habitat?

Um estudo superficial fez crer durante algum tempo que existiam relações fixas onde se harmonizavam o determinismo físico e o determinismo social: as regiões naturais pareciam corresponder na França, ao menos em parte, às antigas

províncias, reunidas umas às outras pela monarquia e por ela mantidas até 1789 em uma agregação um pouco instável.

Foi necessário, examinando as coisas de perto, dar-se conta de que a superposição da província, considerada como região humana, à região natural

\footnotetext{
${ }^{3}$ Terrenos planos próximos a áreas mais elevadas nos quais o escoamento das águas não é definido. (N.T.)
} 
física não repousava sobre nenhum fundamento sério. A Bretanha está inscrita numa região natural, mas ela não compreende toda essa região. Inversamente, a Normandia, velha província homogênea há mil anos, faz parte de ao menos duas regiões naturais bem diferenciadas.

Se há regiões humanas, quer dizer, extensões de território onde os grupos humanos se apresentam, num quadro determinado, com relações constantes de standard of life, de necessidades econômicas, de hábitos sociais e de gêneros de vida, essas regiões humanas não se superpõem de maneira alguma às antigas províncias. Elas também não se superpõem às regiões naturais. Se as características físicas próprias às regiões puderam outrora impor às populações que aí se encontravam certos modos de habitação, de vestimenta, de alimentação, ou de hábitos profissionais e comerciais em relação com a geografia natural, essas modelagens especiais concedidas aos grupos fixados sobre o solo são em grande parte apagadas, ao menos na França, e se apagam um pouco mais todos os dias, à medida em que a vida geral submerge tudo o que restava da vida local: fenômeno relativo bem mais à atividade crescente de circulação do que à onipotência do Estado, à qual geralmente é associado. Os laços entre a região natural e a região humana foram rompidos pela estrada, pelo correio, pela ferrovia, pelo telégrafo e pelo automóvel.

$\mathrm{Na}$ Bretanha interior, há cinquenta anos, construíam-se e cobriam-se as casas com telhas grosseiras, produtos do pays. Comia-se bolinho de trigo sarraceno e batata, produtos do pays. Vestia-se de linho produzido no pays ou de lãs tecidas em rocas do pays. O mobiliário era de camas fechadas, guarda-louças, bancos e armários fabricados no pays.

Tudo isso mais ou menos desapareceu, mesmo nessa região em que as condições naturais pareciam marcadas pelo isolamento. A vida rural, comercial e profissional na Bretanha difere pouco daquela de outras regiões francesas. Seguramente, há novas adaptações às condições de vida permanentes impostas pela natureza.

Mas essas adaptações não têm uma característica regional, elas são localizadas e diversificadas de acordo com os lugares, e também de acordo com a moda, as necessidades ou os interesses estimulados pela vida geral. E isso que se passa na Bretanha, desse ponto de vista, também se passa, no mesmo grau ou de forma ainda mais acentuada, em toda parte.

Hoje, não existe na França uma única região, nem mesmo as regiões de montanha, em que os gêneros de vida, os hábitos sociais, os interesses e as necessidades sejam realmente agrupados sob bandeiras regionais.

As bandeiras sob as quais eles se agrupam podem ser muito maiores, ou muito menores.

Quando os viticultores se agrupam em regiões (região do Midi, por exemplo), isso significa sindicatos de interesses que não têm nada a ver com divisões naturais e divisões humanas, nada que faça lembrar a geografia ou a história. 
Não se percebe que os metalúrgicos sejam regionalistas lorenos ou normandos: seus horizontes são mais amplos. A política econômica aconselhada ou desejada pelos produtores de trigo não tem nada a ver com as características físicas regionais próprias à Picardia, a Brie ou a Beauce.

Veremos, um pouco mais adiante, ao longo deste artigo, o que se pensou das regiões econômicas imaginadas e colocadas em funcionamento de 1917 a 1919.

$\mathrm{Na}$ verdade, divisões muito menores, bem menores que os departamentos e mesmo que os próprios arrondissements ${ }^{4}$, pois formaram em grande parte os districts de 1790, mostram-se singularmente vivazes.

Essas divisões são os pays, quase sempre superpostos aos pagi galo-romanos e, como tais, venerados por sua antiguidade e por sua permanência.

Esses pays coincidem apenas excepcionalmente com os feixes de condições naturais autônomas; é então muito difícil e geralmente impossível traçar-lhes limites físicos, e seus limites históricos oscilaram avançando uns sobre os outros. $\mathrm{O}$ que, por sua vez, os fez eclodir e multiplicar à medida que a Gália se povoava, foi a necessidade de um mercado central onde a população, vivendo em um círculo de raio variável em torno do centro, vinha se abastecer e vender seus produtos. O que fez e manteve o pays foi a cidade-mercado, a market town, como dizem os ingleses.

Existe aí uma necessidade fundamental da vida social e econômica. A maré montante da vida geral pode muito bem reduzir a importância da market town, pode transformá-la de diversas maneiras. Mas ela não a suprime. Por vezes mesmo, ela a desperta, ou a estimula. Os quadros de organização política ou de comando se servem da market town, destacam-na e a reanimam a depender da necessidade. As cidades-mercado, em sua maior parte, entraram no quadro da divisão departamental e com isso nada perderam: essa divisão se apresenta frequentemente como agrupamentos de antigos pays que subsistem ainda nela e é isso que a torna duradoura e viva. A região é uma sombra com três quartos apagados à qual é vão querer devolver a vida; o pays e o departamento são realidades.

\section{Defesa dos departamentos}

O esnobismo contemporâneo menospreza em bloco, sem nada examinar e sem nada saber, a obra da Revolução. Os departamentos não poderiam escapar à crítica. Estes foram apresentados como um recorte arbitrário feito apressadamente pelos revolucionários niveladores, desejosos de fazer tábula rasa do passado.

$\mathrm{Na}$ verdade, não houve nada de tão sábio e de tão bem pensado quanto essa criação da grande Constituinte. Sem ter a mesma envergadura que o sistema

\footnotetext{
${ }^{4}$ Arrondissements correspondem a bairros ou subdivisões intraurbanas (N.T.). 
métrico decimal, a criação dos departamentos é, quase tanto quanto aquele, construída sobre a rocha. O sistema métrico durará enquanto houver homens; os departamentos podem durar enquanto houver uma França.

A obra da Assembleia Constituinte é, ao mesmo tempo, destrutiva e construtiva.

A Constituinte queria destruir na administração e nas relações políticas e jurídicas, entre os cidadãos, qualquer traço do espírito particularista, que ela assimilava ao espírito feudal - esta palavra tomada num sentido amplo, pois existem outras feudalidades além das feudalidades guerreiras e blindadas.

Em seu lugar pretendia-se estabelecer quadros administrativos simples, uniformes, tão cômodos para os agentes de execução do Estado quanto para os cidadãos, e absolutamente destituídos dos privilégios locais e dos costumes ultrapassados.

Para responder ao primeiro objetivo, foram apagados todos os nomes da geografia feudal e monárquica nessas novas divisões. A geografia física foi a única escolhida para fornecer a nova nomenclatura. Para responder ao segundo objetivo, esforçou-se por fazer os departamentos quase iguais em extensão, de modo que todo administrado de uma determinada comuna pudesse, no caso de precisar sair de sua sede administrativa, ir e voltar no decurso um mesmo dia (discurso de Target de novembro de 1789).

Para traçar os limites dos departamentos, entretanto, a Assembleia se preocupa o máximo possível em respeitar os hábitos locais e em fazer coincidir os novos limites com os limites ou zonas de transição entre pays: isso explica o caráter aparentemente bizarro de certas demarcações. Milhares de documentos foram produzidos, todos os interessados foram ouvidos, os limites foram fixados de acordo com o que parecia expressar a vontade geral ${ }^{5}$.

A Constituinte soube assim produzir o novo respeitando as tradições, lá onde ela podia fazê-lo e onde elas pareciam legítimas.

Foi recompensada pela solidez imediata de seu trabalho. Ninguém a contestava, todos os partidos aceitaram-na. O departamento de La Vendée concederá, pouco tempo depois, a mais dramática das adesões. Para uns, ela é monstruosa e criminosa, para outros, é gloriosa, mas, para todos, Azuis e Brancos, ela teve, quase desde o início, seu nome histórico de La Vendée; o Bas-Poitou, o Mauges e os pays de Retz desapareceram. Se Lescure exclama aos seus jovens: "Avante, poitevins!"”, sua viúva, em suas memórias, não fala nunca dos campos e dos heróis de La Vendée.

\footnotetext{
${ }^{5}$ Sobre a formação dos departamentos franceses, ver: Ozouf-Marignier, M.-V. La formation des départements. La représentation du territoire français à la fin du 18è siècle. Paris : EHESS, 1989. (N.T.)

${ }^{6}$ Habitantes da antiga região francesa de Poitou. (N.T.)
} 
Mas não é necessário evocar essas patéticas lembranças. A adesão à divisão departamental se fez, em toda a França, livremente, espontaneamente, sem imposição do Estado.

Tomemos em qualquer departamento as numerosas associações ou organismos privados que não tiveram nenhum lugar no poder central ou nos poderes departamentais. Quando essas associações precisam delimitar seu território, tomam naturalmente o departamento ou suas subdivisões e nunca se viu manifestarem incômodo. Na medida em que o quadro territorial das associações ultrapassa o quadro departamental elas realizam uniões interdepartamentais guardando os limites da Assembleia Constituinte. Este é precisamente o caso das Regiões econômicas estabelecidas de 1917 a 1919. Elas só se tornaram viáveis ao se constituírem como uniões interdepartamentais.

Para afirmar que os departamentos se tornaram antiquados, às vezes apoia-se no próprio princípio de Target: a viagem à sede administrativa, ida e volta, em um dia. A circulação se acelerou de tal modo desde Target e as distâncias diminuíram tanto, que a própria aplicação de seu princípio justificaria, segundo alguns, divisões mais extensas.

É bem fácil responder a essa questão.

Inicialmente, o princípio de Target era um ideal, não uma realidade adquirida de seu tempo. Existiam muitos departamentos onde o estado das comunicações, em 1789, não permitia uma viagem à sede administrativa em um único dia. Target contava com os progressos de viabilidade que se aproximavam, mas não eram ainda uma realidade.

Em seguida, se as distâncias diminuíram, a vida social passou então a ter um ritmo de aceleração completamente novo. Do nosso ponto de vista, uma compensa a outra. Pretende-se, hoje, fazer em duas ou três horas aquilo que outrora se fazia em um dia. É por isso que os departamentos, mesmo com as estradas de ferro e o telégrafo, são tão bem adaptados tanto à vida econômica contemporânea quanto na época de 1789. Talvez até melhor, pois uma grande parte dos progressos alcançados há cento e quarenta anos (caminhos vicinais e ferrovias locais), foram realizados em função da divisão departamental e no quadro desta.

O departamento se revelou então, como quadro de ação do governo e da administração e também como quadro para as iniciativas privadas, um instrumento excelente que em nada diminuiu - até mesmo aumentou - seu valor.

\section{Descentralização}

Devemos ainda examinar uma outra queixa dos regionalistas. Eles dizem que a direção política e administrativa do país é muito centralizada na capital, para onde tudo aflui e de onde tudo irradia. Eles afirmam que, para além dessas grandes 
direções necessárias à unidade nacional - em relação à qual, ademais, os regionalistas autonomistas parecem fazer pouco caso - haveria interesse em resolver a maior parte dos assuntos políticos e administrativos nos próprios pays a que eles se referem e pelos seus próprios interessados. Isso é o que se chama descentralização. Para tanto, ainda segundo os regionalistas, a divisão departamental não é boa: o departamento, quadro que eles consideram artificial, não pode viver de uma vida semiautônoma; a região, natural e histórica, é a única capaz de fazê-lo.

Os leitores que nos seguiram até aqui já sabem que para nós o departamento não é uma divisão artificial e arbitrária. Ele seria assim capaz de viver politicamente de sua própria existência, o que já demonstrou desde os tempos da Constituinte, descentralizadora com imprudência e excesso. $\mathrm{O}$ departamento mostra ainda hoje sua validade, a partir do momento em que os conselhos gerais se tornaram pequenos parlamentos.

Mas, para nós, a questão não é essa. É preciso estar de acordo sobre o que se entende por descentralização.

Para os regionalistas, trata-se da transferência de uma parte dos poderes do Estado soberano, tais como são, para uma quantidade mais ou menos vasta de pequenos Estados em que esses poderes se tornarão mais incômodos e mais insuportáveis do que hoje para os cidadãos, pois estes estarão mais próximos dos meios de comando.

A nosso ver, a verdadeira descentralização significa diminuição do poder do Estado. Exigimos que o Estado central abandone uma quantidade de funções parasitas, estranhas à sua verdadeira missão; não exigimos que ele as transfira a Estados subordinados. E se assumimos tal posição, não é porque somos contra o Estado. Ao contrário. Pensamos que exista apenas um meio de salvar o Estado moderno, é fazer enérgicas punções no inchamento monstruoso do qual ele sofre.

A partir desse excesso, o Estado encontra-se hoje, na França, tomado de paralisia. Suas engrenagens funcionam cada vez com mais dificuldade. A quantidade de interesses coletivos que ele reúne sob sua égide se contrariam e se neutralizam. É preciso de qualquer modo, antes que seja tarde, fazer concessões.

Fazer essas concessões, e não sobrecarregar outro ponto. Isso significa suprimir energicamente numerosas funções na esfera política e administrativa, onde elas se encontram hoje e, por conseguinte, retirá-las dos quadros territoriais delimitados sobre o mapa, quer se trate de departamentos ou de regiões. Entre as funções exageradas do Estado, muitas são francamente inúteis, e desaparecerão sem deixar vestígio. Aquelas que responderem às utilidades coletivas, intelectuais, profissionais ou sociais, se reorganizarão espontaneamente sem enquadramento geográfico ou com quadros móveis, extensíveis ou retráteis. 


\section{O regionalismo material}

Perguntemos agora ao regionalismo seus títulos, de uma forma direta, lembrando sempre que a região, tal como se trataria de constitui-la, seria antes de tudo um quadro territorial, político e administrativo.

A região pode se definir materialmente ou espiritualmente. Ela tem, ou pode ter, características visíveis e não visíveis. As primeiras derivam imediatamente da geografia. As segundas mantêm com ela relações mais ou menos débeis ou distantes, mas isso não significa que não devamos mencioná-las.

O regionalismo material consiste nos gêneros de vida, nos hábitos de trabalho e, em geral, no grau de civilização exterior que se pode constatar sobre um determinado território.

A França feudal se apresentava como um mosaico de civilizações dessa natureza. Este mosaico aos poucos se simplificou. Os traços diferenciais se atenuaram e se fundiram. Uma civilização francesa tomou o lugar das civilizações regionais, da mesma forma que não é prematuro prever uma civilização europeia em que irá se fundir a civilização francesa. Os antigos hábitos e os gêneros de vida regionais apresentam ainda, em cada lugar, sobrevivências meio submersas, que hoje só existem na medida em que não representam nenhuma ameaça à vida geral e não a contradizem. Por vezes, elas são mantidas como peças de museu.

Retomemos o exemplo da Bretanha.

A Bretanha foi até a metade do século XIX uma das províncias francesas onde a vida material era a mais difícil. Nessa época ela tinha uma civilização muito própria. Isso se discernia na habitação, na alimentação, no vestuário, nos hábitos comerciais, nas relações sociais visíveis. Como acontece em casos semelhantes, esse pays isolado do resto era ele próprio muito fracionado. Não existia uma civilização bretã, existiam várias. Apenas por uma miragem da lembrança é que o regionalismo atual tenta unificar a velha Bretanha.

O bretão com seu chapéu de fitas e com longos cabelos, com seu casaco curto, seus calções (bragou-bras), caneleira e seus tamancos, representava um tipo humano que para os franceses do centro parecia ter o efeito de um canaque $^{7}$, tanto mais que a vida material do bretão era, em todos os sentidos, difícil e rude.

Procure agora esse bretão. Não o encontrará a não ser nas festas célticas onde, por algumas horas, os bardes se vestem com ornamentos vistosos com os quais

estariam bastante contrariados se os usassem todo dia. E acredite que esses homens não se alimentam de mingau de trigo mourisco e nem bebem somente água.

Temos então três quartos de século que os restos da antiga civilização bretã desaparecem um após o outro, à medida que cresce a prosperidade do pays e que se

\footnotetext{
${ }^{7}$ Povo autóctone melanésio da Nova Caledônia (N.T)
} 
intensificam, entre ele e seus vizinhos, o intercâmbio de homens, de ideias, de pensamentos, de papel impresso, de mercadorias. Ornamentos masculinos e femininos, velhas casas insalubres, alimentação rude, costumes comerciais das feiras, isolamento no fundo de estradas esburacadas, tudo isso desaparece ao mesmo tempo. O bretão dos campos usa boné, casaco e calça. A bretã dos campos renuncia à touca. Quando vai à cidade, deixa sua touca nos moinhos.

Evidentemente, com essa banalização rápida, o pitoresco da velha Bretanha perde muito. A arte perde também. Pintores, escultores e escritores protestam reiteradamente. Eles tentam fazer sobreviver, pelo menos até certo ponto, os velhos gêneros de vida, as antigas vestimentas, os antigos costumes. Só o conseguem de forma intermitente, através de ressurreições de óperas cômicas e carnaval.

A banalização do povo da Bretanha e o desaparecimento de tudo que restava da velha civilização bretã se fazem com o rigor inexorável das leis que governam o mundo. Pode-se lamentar esse movimento, mas ele não irá parar e nem mesmo conseguiremos diminuir sua velocidade.

Isso que é verdade para a Bretanha é igualmente verdade para todas as províncias francesas que tinham conservado, em suas civilizações, características próprias e relativamente marcantes. Essas características desapareceram ou estão por desaparecer. Assim, não é sobre elas que podem se apoiar os regionalistas para fazer reviver quadros territoriais ultrapassados. Esses são apoios vacilantes que caem uns após os outros, e onde as reminiscências, que podemos enumerar hoje, são quase todas artificiais.

\section{O regionalismo espiritual: Alsácia e Bretanha}

Em matéria espiritual, a posição dos regionalistas parece mais sólida. Pois é fato que os hábitos ancestrais de um povo, sua língua, suas crenças, suas atitudes intelectuais e artísticas, modificam-se muito mais lentamente que seu gênero de vida e sua civilização material.

Irei mais longe. Não é desejável que ao nivelamento dos gêneros de vida corresponda um nivelamento intelectual e moral que rebaixaria as sociedades humanas ao patamar daquelas das formigas e das térmitas.

Particularmente, é necessário que num país como a França, a capital não seja o único foco a acolher a inteligência e os rumos artísticos e morais. Haveria aí um motivo de abastardamento e degeneração que poderia ter efeitos em longo prazo sobre a vida da própria capital.

Nesse ponto de vista, estamos de acordo com os regionalistas - simpatizamos com seus esforços e desejamos que tenham êxito. Mas ainda é preciso entendimento sobre esse tema, e por isso indagamos aos regionalistas: para apoiar e reavivar a vida intelectual das províncias, porque teriam os senhores necessidade 
de um quadro territorial particular de administração e de comando? Esses são dois pontos de vista ou duas ordens de ideias que não têm nada em comum, eles são e devem permanecer estranhos um ao outro.

Consideremos por exemplo isso que nós podemos chamar, se desejarmos, a região do Norte, isto é, o conjunto formado pelos dois departamentos do Norte e Pas-de-Calais. Essa é uma das partes das mais vivas e das mais robustas da França. Ela conserva ainda, como um adorno, algumas características particulares materiais ou espirituais, desde as quermesses até as canções dialetais. Ela tem um sentimento bem vivo de individualidade na nação francesa e de solidariedade entre todos os originários do Norte. Muitas foram as vezes que, durante a guerra, eu escutei canções onde era exaltada a fraternidade entre "os jovens do Norte e de Pas-deCalais".

Essa personalidade vigorosa das pessoas do Norte, favorecida e estimulada pelo trabalho e pela riqueza, traduz-se no pensamento científico e literário, na arte e na organização familiar, nas ardentes paixões políticas e religiosas. Ela faz desses dois departamentos de grandes industriais, de grandes agricultores, de mineradores e operários, um pays onde a vida social é de uma atividade extrema, sempre ligada por todas as suas fibras à vida geral da França, da Europa e do mundo. Se existe uma região viva, é esta.

No entanto, será que vimos essa região reivindicar uma existência à parte, sob a forma de um quadro geográfico particular com um pessoal administrativo e instituições feitas especificamente para ela? Nunca. A vida regional do Norte conhece, no quadro departamental, o mais pleno florescimento. Nenhuma das formas de atividade caras às pessoas do Norte tem necessidade, para se afirmar, de se desgarrar, por pouco que seja, da unidade francesa.

Essa unidade, simbolizada pelos departamentos, não prejudica em nada o regionalismo, naquilo que ele tem de justo e racional.

Para que a unidade e o quadro departamental tenham parecido incômodos aos regionalistas em outros pontos da França, foi preciso que houvesse em algum lugar formas de regionalismo espiritual que se manifestam, discreta ou deliberadamente, hostis à unidade francesa.

Essas formas são encontradas em duas regiões, onde as atividades hostis à unidade são extremamente diferentes: bastante atenuadas e quase inofensivas na primeira, a Bretanha, e agudas e incômodas na segunda, a Alsácia. No entanto, nos dois casos, as forças de divergência são as mesmas: elas provêm do uso, comum entre seu povo, de uma língua estrangeira ao francês, e da ação do clero católico visando manter a dominação moral e, sobretudo, material. Elas se traduzem, na Bretanha, por declamações sem eco e sem poder de influência na massa do povo e, na Alsácia, por uma agitação das mais perigosas a favor da autonomia, isto é, na verdade, a favor do germanismo. 
Metade da Bretanha fala, não mais um dialeto, como às vezes se diz, mas uma verdadeira língua céltica, totalmente estrangeira ao francês e aos dialetos romanos. A administração francesa fez bem por nunca combater essa velha língua do terroir $^{8}$. Contentou-se em almejar que todos os bretões soubessem também o francês, e fez bem assim procedendo. O clero, mestre material e moral de uma grande parte da Baixa-Bretanha, desejaria, antes, ver os baixos-bretões, homens e mulheres, manter exclusivamente o uso de sua língua materna. Mas a maior parte desse clero, devemos reconhecer, não é anti-francesa. Sem dúvida, houve na Bretanha alguns sacerdotes que ousaram dizer, nos dias dolorosos de Charleroi, que a França estava sendo justamente punida por sua impiedade: eles foram repudiados pela maior parte de seus colegas. Quanto à agitação separatista alimentada por alguns magistrados de Rennes e de Quimper, ela é negligenciável.

O caso da Alsácia é bem diferente.

A língua materna, a Muttersprache da Alsácia, é um dialeto, e um dialeto germânico. Ela é, assim, como todos os dialetos, pouco a pouco absorvida pelo dialeto principal, que é o dialeto alemão. Existe na Alsácia uma luta de línguas que na verdade é travada entre o francês e o alemão, o que não passa de um episódio da luta secular pelo domínio das margens do Reno. Como os alsacianos, em sua maior parte, escolhem voluntariamente aprender o francês, essa luta não teria nenhuma gravidade se o clero católico alsaciano não tentasse a qualquer preço manter a Muttersprache e a lutar contra o francês, reputado veículo da impiedade.

Trata-se aqui de dominação material, e não de liberdade de consciência. O clero alsaciano sabe muito bem que em toda a França o exercício de culto católico e absolutamente livre e sem entraves. Se amanhã as leis que são aplicadas no Norte católico e na Bretanha fossem aplicadas na Alsácia, todas as igrejas permaneceriam abertas a todos os fiéis. Só sendo um leitor do jornal Elsaesser Kurier para acreditar no contrário. Mas o clero perderia seu domínio absoluto sobre os bens, sobre as consciências e sobre os votos, e é isso que algumas pessoas não querem. Também há propagandistas que pregam a autonomia e, se necessário, o separatismo; eles o fazem, frequentemente, apoiando-se sobre as pretensas reformas projetadas por imprudentes ideólogos franceses, e sobre o descrédito, não menos imprudente, da obra admirável de unificação realizada pela Assembleia Constituinte.

Já era hora de colocar as coisas em ordem.

\footnotetext{
${ }^{8}$ Sobre o termo "terroir", originalmente ligado a uma porção específica de terra tomada a partir de suas aptidões agrícolas, especialmente no que se refere à economia vitivinicultora, compreendendo ainda as ligações culturais da população local com sua região, ver: Weber, Eugen. La Fin des terroirs. La modernisation de la France rurale, 1870-1914. Paris : Fayard/Éditions recherches, 1983. (N.T.)
} 